\title{
Patients' insight and felt stigma among psychiatric patients
}

\author{
Amal Sobhy Mahmoud, Assistant Prof. Abeer Elsayed Berma, lecturer \\ Psychiatric Nursing and Mental Health, Faculty of Nursing, Port Said University.
}

\begin{abstract}
Aim: Was to explore the relationship between insight and felt stigma among psychiatric patients.

Methods: The research design was descriptive explorative study. The study was carried out in inpatients units and out patients' clinic of Port-Said Psychiatric health hospital, Egypt. A convenient sample of 130 patients from pervious mentioned setting. The tools that are used for data collection were: Birchwood Insight Scale, Felt Stigma Scale, socio-demographic questionnaire and clinical data interview schedule.

Results: The results revealed that, there was a statistically significant relation between patients' diagnosis and insight. The results showed statistically significant relation between patients' insight and its stigma. Psychotic illness contributes to poor insight and high stigma in most schizophrenic patients.

Conclusion: The study concluded that psychotic illness contributes to poor insight and high stigma in most schizophrenic patients. Single patients with previous admission to hospital, living in rural area, all contribute to poor insight in Psychiatric patients.
\end{abstract}

Keywords: Felt Stigma, Insight, Psychiatric patients.

\section{Introduction}

Insight in mental illness refers to a patient's understanding and judgment of his disorder. It is an important marker of recovery from some mental disorders. A common view is that lack of insight is part and parcel of the psychotic state. Insight and psychosis are not synonymous phenomena, and indeed. Another piece of evidence that insight is not simply an aspect of psychosis is the observation that impairment of insight occurs in non-psychotic states $[\mathbf{1}, \mathbf{2}]$.

Poor insight associated with mental disorders is a vital sign of impaired psychosocial products, poorer clinical outcome, low treatment adherence, lower frontal and parietal gray matter volumes and suicidal behavior in patients with severe mental disorders [3-5].

Insight into having a mental disorder represents a complex multidimensional phenomenon. Thus, dimensional rather than dichotomous measures have been widely used to address multiple aspects of insight into illness. These dimensions include awareness of illness, awareness of symptoms, and the perceived need for treatment [6].

The stigmatization of mental illness is common among the general population, psychiatric patients, and their families. These negative attitudes are primarily based on the belief that psychiatric patients are prone to impulsive acts of violence and are incompetent because of their decreased capabilities [7]. Such negative attitudes label psychiatric patients and isolate them from society. Because of the existence of stigma, patients often decrease their expectations about their potential achievements and regard themselves as losers [8]. Stigma delays care for psychological problems and increases the difficulties facing patients with mental illnesses when trying to re-integrate into society after an acute episode of illness. Some authors have described possible reasons for mental disorder-related stigma and possible counter measures $[\mathbf{9 , 1 0 ]}$.

Health-related stigma is a common phenomenon worldwide. Many people suffering from a chronic health condition are stigmatized due to this condition [11]. The stigma associated with mental illness is widespread [12]. Stigma refers to social rejection and is therefore a social construct [13]. There are an increasing number of studies on the subjective experience of stigma amongst mentally ill persons but still few coming from low- and middle-income countries, and very few from Muslim countries [12].

\section{Significance of the study:}

The concept of insight is problematic because it merges several aspects of the mental illness experience that may not related to each other [14]. Stigmatizing attitudes toward people with mental illness are common and remain a burden for the stigmatized individuals as well as a major clinical and public health issue. Stigma surrounding psychiatric patients may result in delayed treatment, thereby increasing risks for health problems, abnormal behavior, and violence. The effects of mental illness stigma on the psychiatric patients include psychological stress, depression and other psychiatric morbidity, fear, marital and relationship problems, restrictions from social participation. 


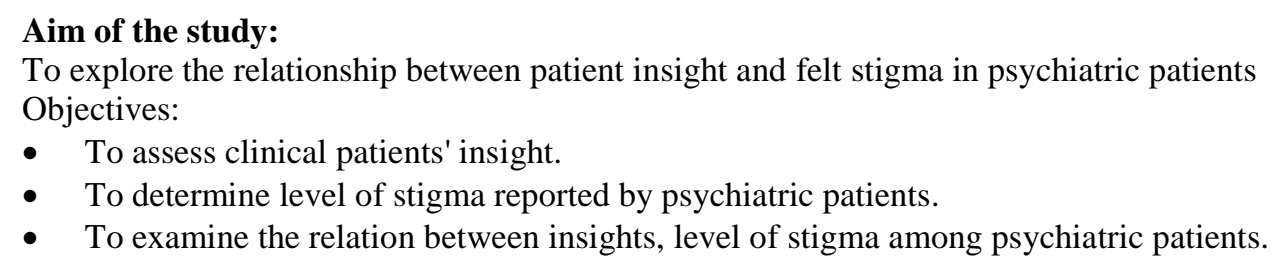

\section{Subjects and Methods}

Research Design: A descriptive explorative study.

Setting: The study was carried out in inpatients units and out patients' clinic in Port-Said Psychiatric hospital, Egypt. The hospital is affiliated to the Ministry of Health and provides inpatient service to the all catchment areas in Port-Said and two surrounding governorates (Ismailia and El Suez). The mental health hospital capacity is 150 beds. The hospital services are free and it composes six inpatients psychiatric units, three units for male patients and two units for female patients. The hospital has ward for drug dependents and psychiatric outpatient clinic.

Subjects: A convenient sample of $\mathbf{1 3 0}$ patients from the inpatients and out patients of Port - Said psychiatric hospital, selected from different diagnosis. Their age older than 20 years, from both sexes, able to share in the study and capable to fill all sheets. The researchers excluded mentally retarded patients and patients with major physical illness as Scabies Patients and Comatose patients.

\section{Tools of Data Collection:}

Tool I: Birchwood Insight Scale

The Birchwood Insight Scale (IS), developed by Birchwood et al. [15], used to evaluate clinical insight. This scale constitutes of eight statements divided into three levels of insight: awareness of illness (2 items), awareness of symptoms ( 2 items) and awareness of the need for treatment (4 items), rated on a 3-point Likert scale (agree - unsure - disagree). Each level is given equal weight when calculating the total score. Higher scores indicate better insight. The total score has a range of 0 to 12 , with a score of 9 or more indicating insightful.

\section{Tool II: Felt Stigma Scale}

The Stigma Scale developed by King et al., [16], used to measure Self Stigma, It constitutes of 28 items, divided into 3 domains namely discrimination (13 items), disclosure (10 items) and positive aspects (5 items), rated on a 3-point Likert scale on which $3=$ 'strongly agree' to $1=$ ' disagree', four negative statements reversed and eleven were positive statements). Thus, high scores reflected higher felt stigma and low scores reflected lower felt stigma (potential range: 15-45). Whereas 15-25 represents low level, 26-35 is medium; and 36-45 is high felt stigma.

\section{Tool III: Socio-demographic questionnaire}

Socio-demographic questionnaire and which included, age, sex, level of education, occupation, marital status, place of residence, religion, family size and monthly income as well as clinical data interview schedule included diagnosis, total duration of illness, number of hospital previous admission, time of hospitalization in the last time and history of family disease.

\section{Pilot Study:}

Thirteen psychiatric patients with different diagnosis were selected from inpatients units and out patients' clinic of Port-Said Psychiatric hospital and later, they were not involved in actual study. The pilot conducted to check and ensure the clarity and applicability of the Felt Stigma Scale and the Birchwood Insight Scale. Some changes in the wording of the Felt Stigma Scale and the Birchwood Insight Scale were done, and the scales were put into final form.

\section{Field Work:}

- The researchers visited inpatients units and out patients' clinic 2 days per week, from 8.30 to 11.30 a.m. after permission from the responsible authorities of Port Said Psychiatric Hospital. The duration of data collection started from $15^{\text {th }}$ of October 2013 to $15^{\text {th }}$ of January 2014.

- The patients' choose according to their previous diagnosis based on check their files.

- The aim of the study was explained to selected patient in the study.

- The verbal informed consent (assent) was obtained. 
- Patients interviewed individually to collect necessary information using clinical data interview schedule, Felt Stigma Scale and the Birchwood Insight Scale respectively. Each patient interviewed from 30-60 minutes.

- Felt Stigma Scale and Birchwood Insight Scale were translated into Arabic Language by the researcher, and retranslated to English by English language expert.

- Felt Stigma Scale and the Birchwood Insight Scale were tested for face validity by five panel experts in the field of psychiatric nursing and medicine and the experts agreed on the two scales items after translation without correction.

- A Reliability test for "the Felt Stigma Scale" and "Birchwood Insight Scale" was done by Cronbach's alpha of 0.783 for the Felt Stigma Scale which was highly acceptable, and for Birchwood Insight Scale which was also acceptable 0.672 .

\section{Ethical Consideration:}

- Confidentiality and privacy were assured.

- The verbal informed consent was obtained

- All participants have the right to withdraw from study at any time.

\section{Statistical Analysis:}

Data were entered into the SPSS software program (version 20.0). Findings were presented in tables. Both descriptive and inferential statistics were used such as mean, percentage, standard deviation, Chi-Squire and ttest. Statistical significant difference was considered when P-Value $\leq 0.05$.

\section{Results}

Table (1) reveals socio-demographic characteristics of the patient in relation to insight and its level of stigma. Patients' age ranges between 21-62 years with a mean age of 34.82 \pm 11.998 years. More than half of the studied patients $(54.0 \%)$ who has lack of insight is aged between 20 to less than 30 years, followed by patients aged 50 years and more $(24.0 \%), 70 \%$ of them male compared to $30.0 \%$ of female patients, more than one third of them $(38.0 \%)$ are in secondary level of education, only $18.0 \%$ of patients are not employed $78.0 \%$ of them are single. All patients who have lack of insight (100\%) from rural area $68.0 \%$ of them have satisfactory monthly income. The results revealed that there is no statistically significant relation between socio-demographic characteristics of the patient and its insight, except in marital status and Place of residency, where of the single patient reported lack of insight $(\mathrm{P}$-value $=.042$. $)$. Patients who live in rural area reported lack of insight $(\mathrm{P}$-value $=\leq 0.05)$.

Felt stigma among patients (53.3\%) are highly, their age between 20 to less than 30 years, $80 \%$ of them male, while $46.7 \%$ of them has basic level of education. Regarding patients' occupation, notice that $73.3 \%$ of them employed $60.0 \%$ of them single, while, $33.3 \%$ from rural area, $40.0 \%$ of them have satisfactory family monthly income. There is no statistically significant relation between the levels of stigma and patient's sociodemographic characteristics except in relation to place of residency (P-value=006).

Table (2) illustrates that clinical characteristic of the patient in relation to insight and its level of stigma; it indicates that, $46.0 \%$ of schizophrenic patients have lack of insight followed by $38.0 \%$ of patients with bipolar affective disorder, manic type. The results revealed that, $90.0 \%$ of patients has lack of insight admitted previously to hospital, more than half of them (51.3\%) admitted from 1 to 2 times previously. Speaking about duration of illness, more than three quarters of studied patients has lack of insight has duration of illness from 1 to 4 years $(78.0 \%), 86.2 \%$ of them not has any family history to psychiatric illness. In relation to levels of stigma, about half of patients has lack of insight has medium felt stigma level $(48.0 \%)$.

The results clear that clinical characteristic of the patient in relation to its insight. There were statistically significant relations between patients diagnosis and insight, the schizophrenic patients were significant lack of insight than the bipolar affective disorder ( $\mathrm{p}$-value $=0.000$ ). Also, there are a statistically significant relation is found between patient's previous admission to hospital and lack of insight ( $\mathrm{p}$-value $=.009$ ) as well as duration of illness (p-value=.012). High felt stigma (46.7\%) schizophrenic patients followed by $20.0 \%$ of patients with drug dependence. $60.0 \%$ of them admitted previously to hospital, $44.4 \%$ of them admitted from 3 to 4 times previously. Concerning duration of illness, about three quarters of studied patients $(73.3 \%)$ has high felt stigma had duration of illness from 1 to 4 years, the majority of them not has any family history to psychiatric illness $(93.3 \%)$. In relation to patients' insight, more than one quarter of patients (73.3\%) felt stigma highly has lack of insight.

A statistically significant relation is found between patient's last time of hospitalization and the levels of stigma $(\mathrm{T}$ Test $=-7.255$ and $\mathrm{P}$-value $=0.000)$ and patient insight and its relationship with the levels of stigma $(\mathrm{P}-$ value $=0.045)$.

Table (3) shows the relation between patients' insight and its stigma score. The table revels that the insightful patients' and patients' with lack of insight have significant level of felt stigma (P-value=0.017). Also there is statistically significant relation between total patients' insight score and its stigma score $(\mathrm{P}-\mathrm{value}=0.000)$. 
Table (4) shows the relation between patients' diagnosis and insight, stigma. As regard patients' insight, most of the drug dependent patients $(53.3 \%)$, nearly half of schizophrenic (46.0\%), bipolar affective disorder, depressant type $40.0 \%$, aware of illness. While only $6.0 \%$ schizophrenic, $24.0 \%$ of depressant patients of bipolar affective disorder and $40.0 \%$ of obsessive compulsive disorder has awareness of the need to treatment. Concerning patient's level of stigma, $80.0 \%$ of the patients with drug dependence, obsessive compulsive disorders (OCD) and $56.0 \%$ of bipolar affective disorder, manic and depressive type and schizophrenic patients, shows positive aspects of stigma.

\section{Discussion}

Stigma contributes to discrimination and human rights violations experienced by people with mental disorders [17]. Stigma has been divided into public and self. Public stigma is the reaction that the general population expresses towards persons with mental disorders. Self-stigma is the prejudice which people with mental disorders turn against themselves. Both public and self-stigma may be understood in terms of three components: stereotypes, prejudice, and discrimination [18].

Regarding patient's insight in relation to the participants' socio-demographic characteristics, there was no significant differences between sub-categories of the most socio-demographic characteristics (age, sex, level of education, occupation and family income) in regard to patients' insight. This result was in the same line with Mintz, Dobson, and Romney [19] found insignificant relation between insight and age at illness onset. Concerning the patients' marital status, the findings of current study revealed significant relation between insight and marital status, single patients reported lack of insight. However, the presence of a partner can be a source of social, psychological as well as a physical support and awareness in married patients. The current study displayed that, patients' clinical characteristics in relation to its insight; there were significant relations between sub-categories of the most clinical characteristics as diagnosis, pervious admission and duration of illness. There were statistically significant relations between lack of insight and schizophrenic patients' than the bipolar affective disorder. This finding may be due to the fact that schizophrenia usually affects the cognitive, affective and behavioral status of the patients. Moreover, psychosis was a syndrome characterized by gross impairments in the ability to assess reality and behave coherently. This result was inconsistent with Amador [20], who reported that, nearly two thirds of the patients with schizophrenia and nearly half of the subjects with manic depression (with psychosis) were unaware of being ill. Similarly, Baier [21] supported the same findings, as they found that, about third to half of schizophrenic patients had poor insight, meaning they may not acknowledge their illness or the need for treatment. Moreover, David, Buchanan, Reed, Almeida [22] found correlation between insight and severity of illness in schizophrenics in a subsequent study.

On the contrary, McEvoy, Apperson, Appelbaum, Ortilip, Brecosky, et al., [23] found no any relation between the insight levels and etiology of illness. Moreover, the changes in insight scores during hospitalization did inconsistently with changes in acute psychopathology. The only significant finding was between overall insight and clinical outcome in schizophrenia. The authors concluded that the lack of insight could not be explained on the basis of psychopathology.

Insightful patients who stigma seems to be more depressed than those who don't. Furthermore the associations of insight with depression, low quality of life, and negative self-esteem are moderated by stigma. Those with lack of insight had problems with service engagement and medication compliance. Insightful patients accompanied by stigmatizing beliefs had the highest risk of experiencing low quality of life, negative self-esteem, and depressed mood. The present study depicted that the men with lower educational level were found to more subjected to stigma than those with higher educational level. While in both genders subjects not living with a spouse in rural area and employed subjects were also more subjected to felt stigma highly, they were more likely than the others to report common mental problems in presence of stigma. This result was supported by McLean, Paxton, Massey, Hay, Mond, et al [24] stated that the men compared with women and lower compared with higher education and income groups held significantly higher stigmatizing attitudes and beliefs. As a result of, Stewart, Jameson, and Curtin [25] stated that older adults living in isolated rural counties demonstrated higher levels of public and self-stigma and lower levels of psychological openness than older adults in urban areas even after accounting for education, employment, and income. Sarkin, Lale, Sklar, Center, Gilmer, et al, [26] contradicted this study and mentioned that, females facing stigma more than males, but males were fewer liable to approve the potentially positive aspects of facing mental health challenges than females.

Concerning patient's socio-demographic characteristics in relation to the level of stigma. There were no significant differences between sub-categories of the most demographic variables (age, sex, level of education, occupation, marital status, and family income). The study by Sarkin et al. [26] found that patients in young age suffering from stigma due problems related to mental health. Poor people with mental illness were more prone to stigma and other unfavorable consequences of mental illness than their counterparts with higher socioeconomic status [27]. 
As a result of, the impact of patients' clinical characteristics, it was evident that schizophrenic patients tended to be felt stigma highest than other disorders. This latter finding may be due to the fact that mental illness usually affects the cognitive, affective and behavioral status of the patients and also suggesting a significant impact of culture which was presumed to more heavily stigmatize mental illness and especially psychosis. However, there is a general belief that 'people with schizophrenia are not able to do things very well,' that 'they will fail. This finding was supported by, Reitan [28], who emphasized that the people with schizophrenia have experienced some form of discrimination, which has hampered their motivates to work. This result was congruent with Murri, Respino, Innamorati, Cervetti, Calcagno, et al [29] who found that the patients with schizophrenia are in long-term contact with specialized services and they perceive stigma arising from such institutions and from health professionals. The current study showed that there were statistically significant relation between the levels of stigma and patients' insight. This is probably due to Self-stigmatization undermines treatment compliance. Its indirect effects can be mediated via stages of change and insight. Mishra, Alreja, Sengar, and Singh [30], Hasson-Ohayon, Tuval-Mashiach [31], Morag-Yaffe, Gaziel, et al [32] were congruent with the currents study. It was found that insightful patient feel stigma highly significant than patients with lack of insight. As well as, Marialuisa, Nicolas, and Roland [33] found that more insight at baseline and an increase in self-stigma. This in contrast with Caputo, Melillo, Elce, Mazza, Colletti, et al (34) who stated that lower levels of insight are related to higher stigma resistance and higher stigma leads to poorer functioning in social contexts. Moreover, Anton [35] who reported that patients with good insight who do not perceive much stigmatization seem to be best off across various outcome parameters. In addition, Bouvet and Bouchoux [36], Anton [35] stated that the relationship between insight and depression is mediated by stigma.

Also literature indicated although the presence of depressive symptoms in schizophrenic patients they report better insight. Consequently, Sarkin, Lale, Sklar, Center, Gilmer, et al [26] reported that, although patients with affective disorders reported more embarrassment with disclosing mental illness than people with schizophrenic disorders. At the same time, they did not report more discrimination than patients with schizophrenic disorders.

\section{Conclusion}

Based on the findings of the present study, it can be concluded that psychotic illness contributes to poor insight and high stigma in most schizophrenic patients. Single patients with previous admission to hospital, living in rural area, all contribute to poor insight in psychotic patients.

Also, there is relation between patient insight and the levels of stigma and between total patients' insight score and its stigma score.

The results from this study indicated that the increased patients awareness of mental illness has reduced the level of stigma surrounding psychiatric patients may result in delayed treatment, thereby increasing risks for health problems, abnormal behavior, and violence.

\section{Recommendations}

1) There is a great need to establish a system of community mental health services that can cover all aspects of psychotic patient's insight as well as their stigma felt.

2) Increase awareness of the mental health team about the importance of dealing holistically with psychotic patients

3) Insight and stigma assessment can be integrated as important part of psychotic patients nursing assessment.

4) Psycho education of psychotic patients should be an important part of their nursing management. This may cover the followings:-

- Improving insight level should be completed by a specific attention to the level and evolution evaluation of internalized stigma.

- Special attention should be given to the possible negative implications that insight possesses.

5) The nurse should be available to the clients and their caregivers during difficult times to provide the psychosocial support needed.

6) It is recommended to study the insight and stigma in a large group of patients with schizophrenia and mood disorders separately

7) Mental health promotion programmers' should aim at educating the public, and particularly men and the lower educated public, on the impact of stigma and their significance.

\section{Further research recommendations:}

- The nurse should be available to the clients and their caregivers during difficult times to provide the psychosocial support needed.

- It is recommended to study the insight and stigma in a large group of patients with schizophrenia and mood disorders separately 


\section{References}

[1]. Ghaemi N. Insights and Psychiatric Disorder: A review of the literature, with a focus on its clinical relevance for Bipolar disorder. Psychiatric Annals 1997; 27: 782-790.

[2]. Mak S, Wu M, Cognitive insight and causal attribution in the development of self-stigma among individuals with schizophrenia. Psychiatric Serv; 2006; 57(12):1800-1802.

[3]. Buckley F, Hrouda R, Friedman L, Noffsinger G, Resnick J, Camlin- Shingler, K. Insight and its relationship to violent behavior in patients with schizophrenia. American Journal of Psychiatry 2004; 161, 1712-1714.

[4]. Schwartz C, Smith D. Suicidality and psychosis: the predictive potential of symptomatology and insight into illness. Journal of Psychiatric Research 2004; 38, 185-191.

[5]. Parellada M, Boada L, Fraguas D, Reig S, Castro-Fornieles J, Moreno D, Gonzalez-Pinto A, Otero S, Rapado-Castro M, Graell M, Baeza I, Arango C. Trait and state attributes of insight in first episodes of early-onset schizophrenia and other psychoses: a 2-year longitudinal study. Schizophrenia Bulletin 2011; 37, 38-51.

[6]. Amador F, Strauss H, Yale A, Flaum M, Endicott J, Gorman M. Assessment of insight in psychosis. American Journal of Psychiatry $1993 ; 150,873-879$.

[7]. Phelan, C., Link G., Stueve, A. and Pescosolido, A. (2000). Public conceptions of mental illness in 1950 and 1996: what is mental illness and is it to be feared? Journal of Health and Social B 2000; 41(2):188- 207.

[8]. Ritsher B, Phelan C. Internalized stigma predicts erosion of morale among psychiatric outpatients. Psychiatry Res; 2004; 129(3): 257-265.

[9]. Lia Q, Tan W, Wan F, Wang, F. Social discrimination on patients with mental disorders: Status quo, reasons, and countermeasures Medicine and Philosophy (Clinical Decision making); 2008; 29(1):69-71 (In Chinese).

[10]. Guo F, Lu C, Zhang H. Experience of discrimination and coping styles of schizophrenia patients in the convalescent period. Chinese Journal of Nursing; 2010; 45(8):677-680 (In Chinese).

[11]. Heijnders M, Van Der Meij S. "The fight against stigma: an overview of stigma-reduction strategies and interventions" Psychology, health \& medicine 2006; 11(3): 353-363.

[12]. Ghanean H, Nojomi M, Jacobsson L. "Internalized stigma of mental illness in Tehran, Iran." Stigma Research and Action, 2011; 1(1): 11-17.

[13]. Crocker J, Park E. "The costly pursuit of self-esteem". Psychological bulletin 2004; 130 (3): 392.

[14]. Kravetz, S., Faust, M., David, M. Accepting the mental illness label, perceived control over the illness and quality of life. Psychiatr. Rehabil. J. 2000; 23, 323-332

[15]. Birchwood M, Smith J, Drury V, Healy J, Macmillan F. Slade M. A Self-report Insight Scale for psychosis: reliability, validity and sensitivity to Change. Acta Psychiatr Scand 1994; 89, 62-67.

[16]. King M, Dino S, Shaw J, Watson R, Stevens S, Passetti F, Serfaty M. The Stigma Scale: development of a standardized measure of the stigma of mental illness. British Journal of Psychiatry, 2007; 19, $248-254$.

[17]. Ngui M, Khasakhala L, Ndetei D, Roberts W. Mental disorders, health inequalities and ethics: A global perspective. International Review of Psychiatry, 2010; 22(3), $235-244$.

[18]. Corrigan W, Watson C. Understanding the impact of stigma on people with mental illness. World Psychiatry 2002; 1(1), 16 - 20.

[19]. Mintz R, Dobson S, Romney M. Insight in schizophrenia: a metaanalysis. Schizophr Res. 2003; 61, 75-88.

[20]. Amador X. Special Report Poor Insight in Schizophrenia: Overview and Impact on Medication Compliance, New York, 2006.

[21]. Baier M. Insight in schizophrenia: a review. Curr Psychiatry Rep, Aug; 2010; 12(4): 356-61.

[22]. David A, Buchanan A, Reed A, Almeida O. The assessment of insight in psychosis. Br. J. Psychiatry 1992; 161, 599-602.

[23]. McEvoy P, Apperson J, Appelbaum S, Ortilip P, Brecosky J, Hammill K, Geller, L, Roth L. Insight in schizophrenia: its relationship to acute psychopathology. J. of Nerv. Ment. Dis. 1989; 177, 43- 47.

[24]. McLean S, Paxton S, Massey R, Hay P, Mond J. Rodgers B. Stigmatizing attitudes and beliefs about bulimia nervosa: gender, age, education and income variability in a community sample, international journal eat disorders, 2014; 47(4):353-61.

[25]. Stewart H, Jameson J, Curtin L. The Relationship Between Stigma and Self-Reported Willingness to Use Mental Health Services Among Rural and Urban Older Adults. sychol Serv 2014; Jan 19. [Epub ahead of print].

[26]. Sarkin A, Lale R, Sklar M, Center K, Gilmer T, Fowler C, Heller R, Ojeda V. Stigma experienced by people using mental health services in San Diego County. Soc Psychiatry Psychiatr Epidemiol 2014; Nov 19. [Epub ahead of print].

[27]. Boyd J, Juanamarga J, Hashemi P. Stigma of Taking Psychiatric Medications among Psychiatric Outpatient Veterans. Psychiatr Rehabil J 2015; Mar 30.

[28]. Reitan A. Stigma and Schizophrenia - A Predetermination of Failure 2014; November 28.

[29]. Murri B, Respino M, Innamorati M, Cervetti A, Calcagno P, Pompili M, Lamis, A, Ghio L, Amorem M. Is good insight associated with depression among patients with schizophrenia? Systematic review and meta-analysis, schizophr research 2015; 162 (1-3):234 247.

[30]. Mishra K, Alreja S, Sengar S, Singh R. Insight and its relationship with stigma in psychiatric patients, Ind Psychiatry J, 2009; 18(1): 39-42.

[31]. Hasson-Ohayon I, Tuval-Mashiach R, Morag-Yaffe M, Gaziel M, Schapir L, Zalsman G, Shoval G. Parents of adolescents with psychiatric disorders: insight into the disorder, self-stigma and parental stress, compr psychiatry 2014; 55(5):1106-10

[32]. Gaziel, M., Hasson-Ohayon I, Morag-Yaffe M, Schapir L, Shoval G. Insight and satisfaction with life among adolescents with mental disorders: Assessing associations with self-stigma and parental insight, European Psychiatry (2015); February; 30(2):329333

[33]. Marialuis C, Nicolas R, Roland V. Is living with psychosis demoralizing? Insight, Self-stigma, and Clinical Outcome among People with Schizophrenia across 1 Year, Journal of Nervous \& Mental Disease, 2014; 202 (7): 521-529.

[34]. Caputo F, Melillo S, Elce C, Mazza C, Colletti C, Orlando S, Casiello M. Stigma, insight and social functioning in psychotic disorders. A sample to begin the investigation, European Psychiatry 2014; 29(1):1.

[35]. Anton S, Mark V, Berge V, Hugo D, Cornelis M.Stigma moderates the associations of insight with depressed mood, low selfesteem, and low quality of life in patients with schizophrenia spectrum disorders, Schizophrenia Research 2009; Volume 115(2-3): 363- 369

[36]. Bouvet C, Bouchoux A. Exploring the relationship between internalized stigma, insight and depression for inpatients with schizophrenia, Article in French 2014. 
Patients' insight and felt stigma among psychiatric patients

Table (1): Socio-demographic characteristics of the patient in relation to insight and its level of stigma.

\begin{tabular}{|c|c|c|c|c|c|c|c|c|c|c|c|c|c|c|c|c|}
\hline \multirow[b]{2}{*}{$\begin{array}{l}\text { Socio-demographic } \\
\text { Characteristics }\end{array}$} & \multicolumn{6}{|c|}{ Levels of Stigma } & \multirow[b]{2}{*}{$\begin{array}{c}\text { Test } \\
\chi^{2}\end{array}$} & \multirow[b]{2}{*}{$\begin{array}{c}\mathrm{p}- \\
\text { value }\end{array}$} & \multicolumn{4}{|c|}{ Insight } & & & \multirow[b]{2}{*}{$\begin{array}{c}\text { Test } \\
\chi^{2}\end{array}$} & \multirow[b]{2}{*}{$\begin{array}{c}\text { p- } \\
\text { value }\end{array}$} \\
\hline & \multicolumn{2}{|c|}{$\begin{array}{c}\text { Low felt } \\
\text { stigma } \\
50\end{array}$} & \multicolumn{2}{|c|}{$\begin{array}{c}\text { Medium } \\
\text { Felt Stigma } \\
65\end{array}$} & \multicolumn{2}{|c|}{$\begin{array}{c}\text { High felt } \\
\text { Stigma } \\
15\end{array}$} & & & \multicolumn{2}{|c|}{$\begin{array}{c}\text { Lack of } \\
\text { Insight } \\
50\end{array}$} & \multicolumn{2}{|c|}{$\begin{array}{c}\text { Insightful } \\
80\end{array}$} & \multicolumn{2}{|c|}{$\begin{array}{c}\text { Total } \\
130\end{array}$} & & \\
\hline Age & & & & & & & & & & & & & & & & \\
\hline $20-$ & 29 & 58.0 & 37 & 59.0 & 8 & 53.3 & & & 47 & 58.7 & 27 & 54.0 & 74 & 56.9 & & \\
\hline 30 - & 4 & 8.0 & 4 & 6.2 & 2 & 13.3 & 2.23 & .973 & 5 & 6.2 & 5 & 10.0 & 10 & 7.7 & 2.72 & .606 \\
\hline $\mathrm{M} \pm \mathrm{SD}$ & \multicolumn{6}{|c|}{$34.82 \pm 11.998$} & \multicolumn{6}{|c|}{ Minimum and Maximum } & \multicolumn{4}{|c|}{ 21- 62} \\
\hline Sex & & & & & & & & & & & & & & & & \\
\hline Male & 40 & 80.0 & 49 & 75.4 & 12 & 80.0 & .399 & .819 & 66 & 82.5 & 35 & 70.0 & 101 & 77.7 & 2.77 & .075 \\
\hline Female & 10 & 20.0 & 16 & 24.6 & 3 & 20.0 & & & 14 & 17.5 & 15 & 30.0 & 29 & 22.3 & & \\
\hline Level of education & & & & & & & & & & & & & & & & \\
\hline Illiterate & 7 & 14.0 & 12 & 18.5 & 2 & 13.3 & & & 10 & 12.5 & 11 & 22.0 & 21 & 16.1 & & \\
\hline Employed & 43 & 86.0 & 52 & 80.0 & 11 & 73.3 & 1.49 & .827 & 81.2 & 41 & 82.0 & 106 & 106 & 81.5 & .070 & .966 \\
\hline NotEmployed & 7 & 14.0 & 13 & 20.0 & 4 & 26.7 & & & 18.8 & 9 & 18.0 & 24 & 24 & 18.5 & & \\
\hline Marital Status & & & & & & & & & & & & & & & & \\
\hline Single & 37 & 74.0 & 47 & 72.3 & 9 & 60.0 & & & 39 & 78.0 & 93 & 71.5 & 93 & 71.5 & & \\
\hline Married & 3 & 6.0 & 7 & 10.8 & 3 & 20.0 & 4.08 & .665 & 5 & 10.0 & 13 & 10.0 & 13 & 10.0 & 8.18 & $.042^{*}$ \\
\hline Divorced & 7 & 14.0 & 8 & 12.3 & 3 & 20.0 & & & 2 & 4.0 & 18 & 13.8 & 18 & 13.8 & & \\
\hline Widow(ed) & 3 & 6.0 & 3 & 4.6 & 0 & 0 & & & 4 & 8.0 & 6 & 4.6 & 6 & 4.7 & & \\
\hline Place of Residency & $*$ & & & & & & & & & & & & & & & \\
\hline Urban & 3 & 6.0 & 5 & 7.7 & 5 & 33.3 & 10.3 & $.006^{*}$ & 16.2 & 0 & 0 & 13 & 13 & 10.0 & 9.03 & $.001 *$ \\
\hline Rural & 47 & 94.0 & 60 & 92.3 & 10 & 66.7 & & & 83.8 & 50 & 100 & 117 & 117 & 90.0 & & \\
\hline Family incomemonth & & & & & & & & & & & & & & & & \\
\hline $\begin{array}{l}\text { Satisfactory } \\
\text { Intermediate }\end{array}$ & $\begin{array}{c}38 \\
5\end{array}$ & $\begin{array}{l}76.0 \\
10.0\end{array}$ & $\begin{array}{c}43 \\
8\end{array}$ & $\begin{array}{l}66.2 \\
12.3\end{array}$ & $\begin{array}{l}6 \\
4\end{array}$ & $\begin{array}{l}40.0 \\
26.7\end{array}$ & 7.06 & .132 & $\begin{array}{l}53 \\
12\end{array}$ & $\begin{array}{l}66.2 \\
15.0\end{array}$ & $\begin{array}{c}34 \\
5\end{array}$ & $\begin{array}{l}68.0 \\
10.0\end{array}$ & $\begin{array}{l}87 \\
17\end{array}$ & $\begin{array}{r}66.9 \\
13.12\end{array}$ & .765 & .682 \\
\hline
\end{tabular}

*significant at $\mathbf{P} \leq \mathbf{0 . 0 5}$

M + SD: Mean and standard deviation $\quad \chi^{2}$ : Qui Square Test

Table (2): Clinical characteristics of the patient in relation to insight and its level of stigma.

\begin{tabular}{|c|c|c|c|c|c|c|c|c|c|c|c|c|c|c|c|c|}
\hline \multirow{3}{*}{ Clinical characteristics } & \multicolumn{6}{|c|}{ Levels of Seigea } & \multirow{3}{*}{$\begin{array}{c}\text { Test } \\
y^{2}\end{array}$} & \multirow{3}{*}{$\begin{array}{c}\mathrm{P}- \\
\text { value }\end{array}$} & \multicolumn{4}{|c|}{ Insight } & \multirow{2}{*}{\multicolumn{2}{|c|}{ Total }} & \multirow{3}{*}{$\begin{array}{c}\text { Test } \\
\chi^{2}\end{array}$} & \multirow{3}{*}{$\begin{array}{c}\text { P- } \\
\text { ralue }\end{array}$} \\
\hline & \multicolumn{2}{|c|}{$\begin{array}{c}\text { Low felt } \\
\text { stigma } \\
50\end{array}$} & \multicolumn{2}{|c|}{$\begin{array}{c}\text { Medium } \\
\text { Felt stigua } \\
65\end{array}$} & \multicolumn{2}{|c|}{$\begin{array}{c}\text { High felt } \\
\text { stigma } \\
15\end{array}$} & & & \multicolumn{2}{|c|}{$\begin{array}{c}\text { Insightful } \\
\mathrm{s0}_{0}\end{array}$} & \multicolumn{2}{|c|}{$\begin{array}{c}\text { Lack of } \\
\text { Insight } \\
50\end{array}$} & & & & \\
\hline & $\mathrm{N}$ & 96 & $\mathrm{~N}$ & $\%$ & $\bar{N}$ & 36 & & & $\mathrm{~N}$ & 3 & $\mathrm{~N}$ & $9 \varepsilon$ & $\mathbf{N}$ & 5 & & \\
\hline \multicolumn{17}{|l|}{ Draposin } \\
\hline Schirophrenia & 18 & 36.0 & 25 & 38.5 & 7 & 46.7 & \multirow{6}{*}{367} & \multirow{6}{*}{ \$35 } & 17 & 33.8 & 23 & 46.0 & 50 & 38.5 & \multirow{6}{*}{35.28} & \multirow{6}{*}{$.000^{\circ}$} \\
\hline -Bipolas Affective Disonder & 11 & 220 & 12 & 18.5 & 2 & 133 & & & 6. & 75 & 19 & 350 & 25 & 19.2 & & \\
\hline (Depresunt type) & & & & & & & & & & & & & & & & \\
\hline $\begin{array}{l}\text {-Bipolar Affective Disorder } \\
\text { (marus type) }\end{array}$ & 10 & 20.0 & 14 & 21.5 & 1 & 6.7 & & & 17 & 21.2 & 8 & 16.0 & 25 & 19.2 & & \\
\hline $\begin{array}{l}\text { Obsessive Compulaive } \\
\text { Denonder OCD }\end{array}$ & 5 & 10.0 & s & 123 & 2 & 13.3 & & & 15 & 18.5 & 0 & 0.0 & is & 11.5 & & \\
\hline $\begin{array}{l}\text { Desorder OCD } \\
\text { Drue Dependence }\end{array}$ & 6 & 120 & 6 & 9.2 & 3 & 20.0 & & & 15 & 18.8 & 0 & 0.0 & 15 & 11.5 & & \\
\hline \multicolumn{17}{|l|}{ Previobas Admission } \\
\hline No & 10 & 200 & 12 & 18.5 & 6 & 40 & \multirow[t]{2}{*}{3.46} & \multirow[t]{2}{*}{177} & 23 & 28.2 & 5 & 10.0 & 28 & 21.5 & \multirow[t]{2}{*}{6.40} & \multirow[t]{2}{*}{$.009 *$} \\
\hline Yes & 40 & 800 & 53 & 815 & 9 & 60 & & & 57 & 71.2 & 45 & 90.0 & 102 & 785 & & \\
\hline $\begin{array}{l}\text { IfYex Number of Pervious } \\
\text { Admission }\end{array}$ & & & & & & & & & & & & & & & & \\
\hline 1.2 times & 17. & 42.5 & 27 & 509 & 3 & 333 & 7.70 & 655 & 24 & 42.1 & 23 & 512 & 47 & 460 & 994 & .077 \\
\hline 3.4 times & 10 & 25.0 & 9 & 17.0 & 4 & 44.4 & & & 18 & 315 & 5 & 111. & 23 & 22.6 & & \\
\hline $3+$ temes & 13 & 32.9 & 17 & 32.1 & 2 & 222 & & & 15 & 26.4 & 17 & 37.7 & 32 & 31.4 & & \\
\hline Time of hespinalization in the & $\operatorname{Tim}$ & & & ASD & & & & & & 14.60 & 18.0 & & & & & \\
\hline Duration of illhess & & & & & & & & & & & & & & & & \\
\hline 14 & 29 & 58.0 & 44 & 67.7 & 11 & 73,3 & 1.73 & 422 & 45 & 362 & 39 & 780 & 84 & 64.6 & 6.37 . & $.012 *$ \\
\hline 4.8 & 21 & 42.0 & 21 & 323 & 4 & 26.7 & & & 35 & 43.8 & 11 & 220 & 46 & 35.4 & & \\
\hline$M-S D$ & & & & & & & & 3.66 & $=1.97$ & & & & & & & \\
\hline Hincay of family Disease & & & & & & & & & & & & & & & & \\
\hline Yes & 7 & 140 & 13 & 200 & 1 & 6.7 & 188 & 390 & 11 & 13.8 & 10 & 20.0 & 21 & 16.2 & 89 & 241 \\
\hline No & 43 & 86.0 & 52 & 800 & 14 & 933 & & & 69 & 86.2 & 40. & 80.0 & 109 & 83.8 & & \\
\hline Insight & & & & & & & & & & & & & & & & \\
\hline Intiptefial & 25 & 56.0 & 41 & 63.1 & 11 & 733 & 160 & $.045^{\circ}$ & & & & & & & & \\
\hline Lack of Inaiph & 22 & 440 & 24 & 369 & 4 & 276 & & & & & & & & & & \\
\hline Stipma & & & & & & & & & & & & & & & & \\
\hline Low felt stipms & & & & & & & & & 28 & 35.0 & 22 & 44.0 & 50 & 35.5 & 1.595 & 451 \\
\hline Meduen for unigna & & & & & & & & & 41 & 31.2 & 24 & 45.0 & 65 & 50.0 & & \\
\hline High felt Stigma & & & & & & & & & II & 13.8 & 4 & 80 & 15 & 115 & & \\
\hline
\end{tabular}

*significant at $\mathbf{P} \leq \mathbf{0 . 0 5} \quad \mathbf{M}+\mathrm{SD}$ : Mean and standard deviation $\chi^{2}:$ Qui Squar 
Table (3): Relation between patients' insight and its stigma score.

\begin{tabular}{|l|l|l|l|l|l|}
\hline & N 130 & \% & Stigma Score M + SD & T & p- value \\
\hline Insight & & & & & \\
Insightful & 80 & 61.5 & $28.237 \pm 7.626$ & 2.429 & $.017 *$ \\
$\quad$ Lack of Insight & 50 & 38.5 & $24.880 \pm 7.731$ & & $.000^{*}$ \\
\hline Total insight & & & $18.69 \pm 7.832$ & 27.214 & \\
\hline
\end{tabular}

*Significant at $\mathbf{P} \leq 0.05$ T: $T$ test $\mathrm{M}+\mathrm{SD}$ : Mean and standard deviation

Table (4): Relation between patients' diagnosis and insight, stigma.

\begin{tabular}{|c|c|c|c|c|c|c|c|c|c|c|}
\hline & \multicolumn{10}{|c|}{ Diagnosis } \\
\hline & \multirow{2}{*}{\multicolumn{2}{|c|}{$\begin{array}{l}\text { Schizophrenia } \\
50 \\
\end{array}$}} & \multicolumn{4}{|c|}{ Bipolar Affective Disorder } & \multirow{2}{*}{\multicolumn{2}{|c|}{$\begin{array}{l}\text { OCD } \\
15 \\
\end{array}$}} & \multirow{2}{*}{\multicolumn{2}{|c|}{$\begin{array}{l}\text { Drug Dependence } \\
15\end{array}$}} \\
\hline & & & $\begin{array}{l}\text { Del } \\
25\end{array}$ & sant type & $\begin{array}{l}\mathrm{Ma} \\
25\end{array}$ & type & & & & \\
\hline & $\mathrm{N}$ & $\%$ & $\mathrm{~N}$ & $\%$ & $\mathrm{~N}$ & $\%$ & $\mathrm{~N}$ & $\%$ & $\mathrm{~N}$ & $\%$ \\
\hline $\begin{array}{l}\text { Insight } \\
\text { Awareness of: - } \\
\text {-illness } \\
\text {-symptoms } \\
\text {-the need for treatment }\end{array}$ & $\begin{array}{l}23 \\
12 \\
3\end{array}$ & $\begin{array}{l}46.0 \\
24.0 \\
6.0\end{array}$ & $\begin{array}{l}10 \\
0 \\
6\end{array}$ & $\begin{array}{l}40.0 \\
0 \\
24.0\end{array}$ & $\begin{array}{l}4 \\
6 \\
0\end{array}$ & $\begin{array}{l}16.0 \\
24.0 \\
0\end{array}$ & $\begin{array}{l}5 \\
0 \\
6\end{array}$ & $\begin{array}{l}33.3 \\
0 \\
40.0\end{array}$ & $\begin{array}{l}8 \\
0 \\
0\end{array}$ & $\begin{array}{l}53.3 \\
0 \\
0\end{array}$ \\
\hline $\begin{array}{l}\text { Stigma } \\
\text {-Disclosure } \\
\text {-Discrimination } \\
\text {-Positive Aspects }\end{array}$ & $\begin{array}{l}7 \\
25 \\
28\end{array}$ & $\begin{array}{l}14.0 \\
50.0 \\
56.0\end{array}$ & $\begin{array}{l}5 \\
12 \\
14\end{array}$ & $\begin{array}{l}20.0 \\
48.0 \\
56.0\end{array}$ & $\begin{array}{l}5 \\
15 \\
14\end{array}$ & $\begin{array}{l}20.0 \\
60.0 \\
56.0\end{array}$ & $\begin{array}{l}3 \\
9 \\
12\end{array}$ & $\begin{array}{l}20.0 \\
60.0 \\
80.0\end{array}$ & $\begin{array}{l}2 \\
8 \\
12\end{array}$ & $\begin{array}{l}13.3 \\
53.3 \\
80.0\end{array}$ \\
\hline
\end{tabular}

